\title{
THE EFFICACY OF SELECTED BARIATRIC SURGERY METHODS ON LIPID AND GLUCOSE METABOLISM: A RETROSPECTIVE 12-MONTH STUDY
}

\author{
Marek Bužga', Petra Marešová2, Karin Petřeková1, Pavol Holéczy', Kamil Kuča ${ }^{2}, 3$ \\ ${ }^{1}$ Research Obesity Centre, Faculty of Medicine, University of Ostrava, Ostrava, Czech Republic \\ ${ }^{2}$ Faculty of Informatics and Management, University of Hradec Králové, Hradec Králové, Czech Republic \\ ${ }^{3}$ Biomedical Research Centre, University Hospital Hradec Králové, Hradec Králové, Czech Republic
}

\begin{abstract}
SUMMARY
Objective: Approximately $25 \%$ of the Czech population is currently obese. Obesity rates are expected to increase in the future. Obesity not only raises the risk of health complications for individuals, but increasing rates also represent a significant and steadily growing economic burden for healthcare systems and society as a whole. The aim of this study was to evaluate the therapeutic efficacy of three methods of bariatric surgery: laparoscopic greater curve plication (LGCP), laparoscopic sleeve gastrectomy (LSG), and Roux-en-Y gastric bypass (RYBG) in patients with type 2 diabetes mellitus (DM). This study examined the influence of bariatric surgery on body weight and BMl, changes in serum glucose and markers of lipid metabolism.

Methods: This study evaluated outcomes in 74 patients with type 2 DM who underwent LGCP, LSG or RYGB. Patient selection followed guidelines of the International Federation for the Surgery of Obesity, i.e. BMI $\geq 40 \mathrm{~kg} / \mathrm{m}^{2}$ or BMl $\geq 35 \mathrm{~kg} / \mathrm{m}^{2}$ with associated comorbidities or BMl $<35$ $\mathrm{kg} / \mathrm{m}^{2}$. For each of the procedures, the hypotheses were tested with the Bonferroni method.

Results: Statistically significant weight loss, $20.2 \pm 9.3 \mathrm{~kg}$ on average, occurred by 12 months after surgery, with maximum weight reduction of $38 \mathrm{~kg}$. Over the 12-month period, average fasting glycaemia decreased by $2.58 \mathrm{mmol} / \mathrm{L}$ after LGCP, by $2.01 \mathrm{mmol} / \mathrm{L}$ after LSG, and by 4.64 $\mathrm{mmol} / \mathrm{L}$ after RYGB. Triacylglycerol (TGC) values decreased significantly with all procedures. The mean decrease was $1.35 \mathrm{mmol} / \mathrm{L}$ after LGCP and $1.06 \mathrm{mmol} / \mathrm{L}$ after LSG. The greatest TGC concentration decrease, $1.92 \mathrm{mmol} / \mathrm{L}$, occurred after RYGB. Average concentrations decreased below $1.7 \mathrm{mmol} / \mathrm{L}$. There was a statistically significant difference in body weight and BMl reduction between LGCP and LSG groups, as well as between LGCP and RYGB groups. A significant difference in the glucose decrease was observed between the LSG and RYGB groups, which can be explained by the fact that glycaemia and $\mathrm{HbA} 1 \mathrm{c}$ levels were different between these groups prior to surgery.

Conclusions: The best results from the carbohydrate metabolism point reached the malabsorption method RYGB. However, the other two restrictive methods also achieved very good results. In particular, the LGCP method has not only the effect on weight reduction but also on metabolic functions and consequently points to potential healthcare expenditure savings.
\end{abstract}

Key words: bariatric surgery, case study, Czech Republic, LGCP, LSG, RYGB outcomes

Address for correspondence: K. Kuča, Biomedical Research Centre, University Hospital Hradec Králové, Rokitanského 62, 50003 Hradec Králové, Czech Republic. E-mail: kamil.kuca@fnhk.cz

https://doi.org/10.21101/cejph.a4637

\section{INTRODUCTION}

Over the past 20 years, the prevalence of obesity has increased almost twofold in most European countries, including the Czech Republic. Obesity currently affects 10 to $25 \%$ of men and 10 to $30 \%$ of women in Europe. The situation is even graver in the US, where obesity affects $34 \%$ of the adult population; $5 \%$ of the adult population in the US suffers from class III morbid obesity (1). In countries of the Central and Eastern Europe, including the Czech Republic, the prevalence of obesity stands as a forefront issue in all epidemiological studies. Results of the latest large epidemiological study, conducted in the Czech Republic, reveal $30 \%$ of the Czechs to be overweight and $25 \%$ as suffering from obesity. It is an alarming fact that, during the recent 6 years only, the number of obese subjects has increased by $5 \%$ in the total population of 10.3 million, what makes 425,000 people (2).
Recently, a series of epidemiologic studies has evidenced a close link between morbid obesity and type 2 diabetes mellitus (DM), hypertension, hyperlipidemia, obstructive sleep apnea, metabolic syndrome, and insulin resistance $(3,4)$. The scale of the problem is also confirmed by the fact that obesity, when exceeding $40 \mathrm{~kg} / \mathrm{m}^{2}$, shortens life span, on average by 20 years, while obesity consequences are more severe than the consequences of tobacco smoking or alcohol consumption (5).

The treatment of obese patients is a demanding and long-term undertaking, in which there are no "short cuts" or "quick fixes". Literature data clearly show that no weight loss after pharmacotherapy or dietotherapy remains effective in a long run $(6,7)$. Today, surgical treatment of higher obesity levels is undoubtedly the most effective procedure with the best outcomes in a long time perspective (8). Dramatic weight loss leads to improvement of associated comorbidities as well. The results of studies, 
published in the recent decade, have demonstrated that weight reduction by $35-40 \%$, following surgical intervention treatment of obesity, may be regarded permanent, as it is maintained for more than 5 years $(9)$.

The purpose of this study was to evaluate the therapeutic efficacy of three bariatric surgery procedures, the laparoscopic greater curve plication (LGCP), laparoscopic sleeve gastrectomy (LSG), and Roux-en-Y gastric bypass (RYGB) methods, in obese patients with type $2 \mathrm{DM}$. The following variables were assessed 12 months after surgery versus preoperatively:

- Changes in body weight and BMI;

- Changes in serum glucose and lipid metabolism markers.

\section{MATERIALS AND METHODS}

\section{Design}

The study in patients following LSG, RYGB and LGCP was carried out between March 2012 and February 2016 at the Obesitology Research Centre of the University of Ostrava, Czech Republic, and at the Bariatric Surgery Centre, Vítkovice Hospital, Czech Republic. Inclusion criteria included BMI $\geq 40 \mathrm{~kg} / \mathrm{m}^{2}$ or $\geq 35 \mathrm{~kg} / \mathrm{m}^{2}$ with comorbidities or BMI $<35 \mathrm{~kg} / \mathrm{m}^{2}$, and age $18-65$ years, as per the International Federation for the Surgery of Obesity (IFSO) criteria (10). Exclusion criteria included BMI $>50 \mathrm{~kg} /$ $\mathrm{m}^{2}$, any prior abdominal surgery, diagnoses for gastric or duodenal ulcers, thyroid gland disease, and gastrointestinal disease.

For each of the procedures, the following hypotheses were tested:

H1: There will be a total body weight and BMI reduction 12 months after surgery without a significant difference among individual procedure groups.

$\mathrm{H} 2$ : Serum glucose and lipid metabolism markers will change by 12 months after surgery without a significant difference among individual procedure groups.

\section{Statistical Analysis}

The hypotheses were tested with the Bonferroni method (11). Normality of data distribution was assessed on the basis of skewness and kurtosis. Data with normal distribution were tested with the paired t-test, and data without normal distribution with the paired Wilcoxon test. The statistical tests were evaluated at a $5 \%$ level of significance. MS Excel was used for processing.

\section{RESULTS}

The research set included 74 patients, 23 men and 51 women. Patient age ranged from 33 to 65 years, with a mean of $52.7 \pm 9.1$ years. The mean age of the men was 54.2 years; that of the women was 52.0 years. Most patients who undergo bariatric procedures have obesity of a higher class. There were no patients under 30 years of age in the study, which corresponds with the fact that occurrence of type $2 \mathrm{DM}$ in the population increases with age. Thirty-nine percent of the patients underwent LGCP, 38\% underwent RYGB, and $23 \%$ underwent LSG.

\section{Changes in Body Weight and BMI}

The mean body weight of patients who underwent LGCP surgery was $118.7 \pm 15.2 \mathrm{~kg}$ (range: $83-153 \mathrm{~kg}$ ); the corresponding BMI was $41.7 \pm 4.1 \mathrm{~kg} / \mathrm{m}^{2}$ (range: $31.0-49.0 \mathrm{~kg} / \mathrm{m}^{2}$ ). Statistically significant weight loss, $20.2 \pm 9.3 \mathrm{~kg}$ on average, occurred by 12 months after surgery, with maximum weight reduction of $38 \mathrm{~kg}$. Mean total weight loss in percent (\%TWL) was $18 \%$. Mean BMI after surgery was $33.8 \mathrm{~kg} / \mathrm{m}^{2}$ (Table 1 ).

Mean patient weight before LSG was $127.3 \pm 20.2 \mathrm{~kg}$ (range: $100-177 \mathrm{~kg}$ ) and mean BMI was $42.9 \pm 5.7 \mathrm{~kg} / \mathrm{m}^{2}$ (range: $33.0-56.0$ $\mathrm{kg} / \mathrm{m}^{2}$ ). Follow-up 12 months after surgery revealed an average weight loss of $31.3 \pm 12.2 \mathrm{~kg}(25 \% \mathrm{TWL})$, with maximum reduction of $59 \mathrm{~kg}$. The average BMI reduction was $10.5 \pm 4.7 \mathrm{~kg} / \mathrm{m}^{2}$ (Table 1).

The average body weight of RYGB patients before surgery was $118.8 \pm 19.9 \mathrm{~kg}$ (range: $85-168 \mathrm{~kg}$ ). Mean BMI was $43.4 \pm$ $6.5 \mathrm{~kg} / \mathrm{m}^{2}$ (range: $33.8-59.5 \mathrm{~kg} / \mathrm{m}^{2}$ ). Weight loss was similar to that of the LSG patients; however, the mean \% TWL was 30\%, with average weight after surgery of $84.4 \pm 16.7 \mathrm{~kg}$. BMI fell to $30.9 \pm 4.6 \mathrm{~kg} / \mathrm{m}^{2}$.

Figure 1 compares BMI before surgery to BMI 1 year after surgery, according to bariatric procedure. The mean values for patients undergoing all procedures were above $40 \mathrm{~kg} / \mathrm{m}^{2}$, corresponding to Class III obesity. One year after surgery, the mean values had decreased to $30-35 \mathrm{~kg} / \mathrm{m}^{2}$, corresponding to class I obesity.

\section{Serum Glucose and Lipid Metabolism Markers}

Evaluation of individual laboratory parameters was based on the recommendations of the Czech Diabetes Society (12). Glycaemia $\leq 6.0 \mathrm{mmol} / \mathrm{L}$ and glycated haemoglobin $(\mathrm{HbA} 1 \mathrm{c}$ )

Table 1. Weight loss and BMI decrease according to bariatric procedure $(N=74)$

\begin{tabular}{|c|c|c|c|c|c|c|c|c|c|c|}
\hline & \multicolumn{3}{|c|}{ RYGB } & \multicolumn{3}{|c|}{ LSG } & \multicolumn{3}{|c|}{ LGCP } \\
\hline & & $\mathrm{n}$ & Mean & SD & $\mathrm{n}$ & Mean & SD & $\mathrm{n}$ & Mean & SD \\
\hline Before surgery & \multirow{3}{*}{$\begin{array}{c}\text { Weight } \\
(\mathrm{kg})\end{array}$} & 28 & 118.8 & 19.9 & 28 & 127.3 & 20.2 & 29 & 118.7 & 15.2 \\
\hline 1 year after surgery & & 26 & 84.4 & 16.7 & 26 & 84.4 & 13.5 & 26 & 97.8 & 13.5 \\
\hline Weight loss & & 26 & 34.6 & 11.5 & 26 & 31.3 & 12.2 & 26 & 20.2 & 9.3 \\
\hline Before surgery & \multirow{3}{*}{$\begin{array}{c}\text { BMl } \\
\left(\mathrm{kg} / \mathrm{m}^{2}\right)\end{array}$} & 28 & 43.4 & 6.5 & 28 & 42.9 & 5.7 & 29 & 41.7 & 4.1 \\
\hline 1 year after surgery & & 26 & 30.9 & 4.6 & 26 & 31.3 & 12.2 & 26 & 33.8 & 3.5 \\
\hline BMI reduction & & 26 & 13.9 & 4.4 & 26 & 10.5 & 4.7 & 26 & 7.4 & 3.1 \\
\hline Mean total weight loss & $(\%)$ & 26 & 29.1 & 10.1 & 26 & 15.9 & 14.1 & 26 & 17.1 & 14.2 \\
\hline
\end{tabular}


$<4.5 \%$ ( $<4.8 \%$, according to the International Federation of Clinical Chemistry) were considered a therapeutic success. Over the 12-month period, average fasting glycaemia decreased by 2.58 $\mathrm{mmol} / \mathrm{L}$ after LGCP, by $2.01 \mathrm{mmol} / \mathrm{L}$ after LSG, and by 4.64 $\mathrm{mmol} / \mathrm{L}$ after RYGB. As shown in Fig. 2, glycaemia decreased below $6 \mathrm{mmol} / \mathrm{L}$ with all procedures.

The changes were significant for all procedures. Mean $\mathrm{HbA1c}$, which reflects fluctuations of blood glucose within the previous month, decreased significantly by $1.04 \%$ in the LGCP patients and by $1.8 \%$ in the LSG patients. The greatest mean HbA1c decrease, $2.97 \%$, occurred in the RYGB group. HbA1c concentration decreased below $4.5 \%$ after all procedures. Comparisons of glucose metabolism parameters are presented in Figure 2.

Mean total cholesterol increased by 0.14 and $0.34 \mathrm{mmol} / \mathrm{L}$ for LGCP and LSG, respectively, but the difference was not statistically significant. In contrast, RYGB led to a statistically significant mean total cholesterol decrease of $0.85 \mathrm{mmol} / \mathrm{L}$. RYGB likewise led to a statistically significant decrease in LDL cholesterol of 0.82 $\mathrm{mmol} / \mathrm{L}$. LGCP and LSG procedures caused only small changes without statistical significance. HDL cholesterol increased significantly with all surgical procedures. The greatest mean HDL increase $(0.58 \mathrm{mmol} / \mathrm{L})$ occurred with the LSG procedure. LGCP resulted in a mean $\mathrm{HDL}$ increase of $0.37 \mathrm{mmol} / \mathrm{L}$, the smallest increase $(0.23 \mathrm{mmol} / \mathrm{L})$ was seen with RYGB.

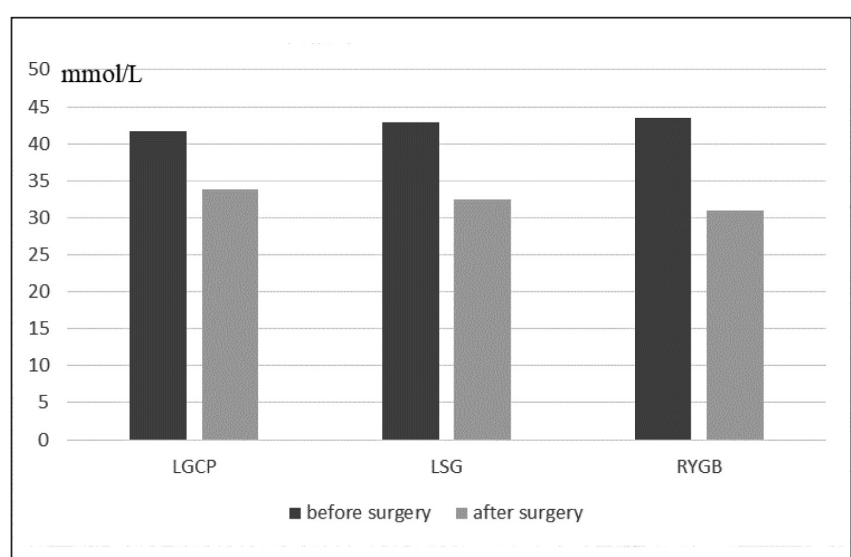

Fig. 1. Comparison of mean BMI values before and 1 year after surgery.

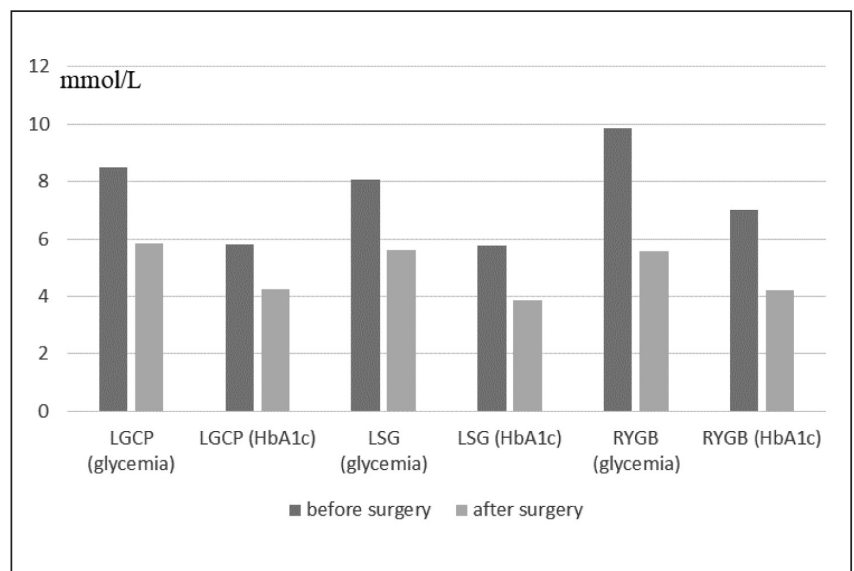

Fig. 2. Comparison of mean glucose metabolism values before and 12 months after surgery.
Triacylglycerol (TGC) values decreased significantly with all procedures. The mean decrease was $1.35 \mathrm{mmol} / \mathrm{L}$ after LGCP and $1.06 \mathrm{mmol} / \mathrm{L}$ after LSG. The greatest TGC concentration decrease, $1.92 \mathrm{mmol} / \mathrm{L}$, occurred after RYGB. Average concentrations decreased below $1.7 \mathrm{mmol} / \mathrm{L}$.

Based on the Bonferroni comparison, there was a statistically significant difference in blood glucose levels between the LSG and RYGB groups. Differences in blood glucose between LGCP and LSG groups, as well as between LGCP and RYGB groups, were not significant. (Table 2).

\section{DISCUSSION}

Bariatric procedures are, at present, the only effective solution for obesity in terms of yielding a sustainable long-term

Table 2. Bonferroni comparison of procedures based on changes in laboratory parameters

\begin{tabular}{|c|c|c|}
\hline & LSG & LGCP \\
\hline \multicolumn{3}{|c|}{ Comparison based on glycaemia } \\
\hline LGCP & 0.57 & \\
\hline $\mathrm{p}$-value & NS & \\
\hline RYGB (tested difference) & 2.63 & 2.06 \\
\hline $\mathrm{p}$-value & 0.017 & NS \\
\hline \multicolumn{3}{|c|}{ Comparison based on glycated haemoglobin } \\
\hline LGCP & -0.77 & \\
\hline $\mathrm{p}$-value & NS & \\
\hline RYGB (tested difference) & 1.16 & 1.94 \\
\hline $\mathrm{p}$-value & NS & 0.001 \\
\hline \multicolumn{3}{|c|}{ Comparison based on total cholesterol } \\
\hline LGCP & -0.20 & \\
\hline $\mathrm{p}$-value & NS & \\
\hline RYGB (tested difference) & 1.19 & 0.99 \\
\hline$p$-value & 0.007 & 0.026 \\
\hline \multicolumn{3}{|c|}{ Comparison based on HDL cholesterol } \\
\hline LGCP & -0.22 & \\
\hline $\mathrm{p}$-value & NS & \\
\hline RYGB (tested difference) & 0.35 & 0.14 \\
\hline$p$-value & 0.035 & NS \\
\hline \multicolumn{3}{|c|}{ Comparison based on LDL cholesterol } \\
\hline LGCP & -0.01 & \\
\hline $\mathrm{p}$-value & NS & \\
\hline RYGB (tested difference) & 0.89 & 0.91 \\
\hline p-value & 0.047 & 0.037 \\
\hline \multicolumn{3}{|c|}{ Comparison based on triacylglycerols } \\
\hline LGCP & 0.30 & \\
\hline $\mathrm{p}$-value & NS & \\
\hline RYGB (tested difference) & 0.86 & 0.57 \\
\hline$p$-value & NS & NS \\
\hline
\end{tabular}

NS - not significant 
body weight reduction and decrease in the incidence of obesityassociated comorbidities (13). LSG is one of several standard procedures, inclusive of RYGB. LSG is particularly popular due to its simplicity, safety, and high efficacy in resolving morbid obesity (14). Conversely, LGCP is a newer bariatric technique that warrants attention because of its results, although it is yet to be accepted by practitioners as a standard procedure. Although LGCP is categorized as a restrictive bariatric surgical procedure, some authors ascribe no metabolic component to this surgery (i.e. decreased ghrelin secretion, changes of serum lipids) (15). On the other hand, our data, together with recent studies, demonstrates LGCP's indisputable restrictive impact, together with an endocrine effect (16). Comparing the results achieved in patient cohorts having undergone either procedure provides important data with which to inform decision-making in terms of the appropriate course of action in resolving obesity in individual patients.

Obesity, jointly with the fat tissue share close to $50 \%$, is among significant risk factors of cardiovascular and metabolic disorders. Health risks associated with obesity increase with growing volumes of intra-abdominal adipose tissue. From this perspective, there has been a high positive reduction in body weight and BMI, observed in our study. In terms of success, DeAquino (17) defines bariatric procedures as successful if patients demonstrate weight loss below $25 \%$ of their preoperative level, satisfactory, if they lose $25-30 \%$ of their preoperative weight, and very good if the weight loss is above $30 \%$ of its total preoperative value. Consequently, our results of weight reduction can be evaluated as successful and comparable with the results of similar studies of patients after bariatric procedures such us laparoscopic sleeve gastrectomy or laparoscopic gastric plication $(18,19)$.

The main obesity-related metabolic risk factors of the cardiovascular disease involve low serum HDL cholesterol levels with increased levels of triacyglycerols (TG) and LDL cholesterol levels.

During twelve months after the surgical intervention, significant changes in the lipid profile were reported, specifically an increase of HDL cholesterol and decreased of triacylglycerols (in all of the cohorts). On the other hand, no statistically significant changes were reported in total in LDL cholesterol levels. Similar results were obtained by Strain et al. (20). One year after LSG, they reported a significant increase of HDL cholesterol levels, while, similarly as in our study, LDL and total cholesterol remained unchanged.

Regarding the cardiovascular risks, the observed increased HDL cholesterol and decreased TG levels are fairly positive, prognostic factors. Similar results were also obtained by Vidal et al.(21) with a significant improvement of lipid profile following LSG (improved hypertriglyceridaemia in $80 \%$ of the group and increased HDL cholesterol in $50 \%$ of the group), including reduced risk for the metabolic syndrome. Apart from dyslipidaemia, the positive changes after LSG and RYGB include a therapeutic impact on other obesity-connected comorbidities; following the operation, more than $75 \%$ of patients demonstrated an improved control of diabetes mellitus within 3 years $(22,23)$.

Our follow-up data confirmed the statistically significant influence of LSG, RYGBP and LGCP on glucose homeostasis, confirming reduced blood glucose and the correction of $\mathrm{HbAl} \mathrm{c}$ in agreement with previous data (24). The positive effect on glucose homeostasis can be attributed to a reduction of insulin resist- ance, increased insulin secretion, and improved tissue responses to insulin (25). Slater et al. (26) stated that positive effects on the glycaemic curve and remission in type $2 \mathrm{DM}$ patients were evident before a pronounced body weight reduction. This leads us to suggest complex roles for the gastric hormones ghrelin and YY peptide in the regulation of pancreatic endocrine function and systemic insulin resistance. Post-operative diet is another factor that influences glucose homeostasis. These findings illustrate that, like LSG, RYGB including LGCP also has a metabolic effect, agreeing with a short-term study $(13,27)$ reporting that $96.9 \%$ of type $2 \mathrm{DM}$ patients exhibited (at the least) some improvement of their preoperative diabetic status 6 months after LGCP, with pre- and postprandial improvement of insulin sensitivity $(16,28)$.

\section{CONCLUSION}

Bariatric surgery has a positive effect on the treatment of obesity. After twelve months there was a significant reduction in weight and BMI without a statistical difference between LSG and RYGB, but a significant decrease was recognized in LGCP patients. At the same time, there has been a change in lipid metabolism in patients. The increase in serum HDL cholesterol, which was more significant in LSG and LGCP, and a decrease in the concentration of triacylglycerols, which was the most significant in RYGB, is essential. In total cholesterol and LDL cholesterol, there was a significant decrease in RYGB alone.

Good restriction results were obtained following LGCP, which might be mediated via altered glucose metabolism and gastrointestinal hormones. Nevertheless, this method is less effective than LSG and RYGB, possibly due to its preservation of the entire stomach, including secretory regions. LGCP could however be useful (particularly) for patients who refuse malabsorption and metabolic procedures, or for those concerned with the irreversibility of LSG and RYGB.

\section{Acknowledgement}

This study was supported by a grant from the Ministry of Education of the Czech Republic, allocated via the University of Ostrava under registration number IRP201549, University of Hradec Králové internal grant Excellence 2018.

\section{Conflict of Interests}

None declared

\section{Adherence to Ethical Standards}

The study was approved by the Ethics Committee at the Faculty of Medicine, University of Ostrava in accordance with the ethical standards of the Helsinki Declaration of 1975, as amended in 2000. Informed consent was obtained from all participants included in the study. The study had a retrospective design (ClinicalTrials.gov registration: NCT02893891).

\section{REFERENCES}

1. Finkelstein EA, DiBonaventura Md, Burgess SM, Hale BC. The costs of obesity in the workplace. J Occup Environ Med. 2010 Oct;52(10):971-6.

2. Matoulek M, Svačina Š, Lajka, J. The incidence of obesity and its complications in the Czech Republic. Vnitr Lek. 2010;56(10):1019-27. (In Czech.) 
3. Nguyen NT, Magno CP, Lane KT, Hinojosa MW, Lane JS. Association of hypertension, diabetes, dyslipidemia, and metabolic syndrome with obesity: findings from the National Health and Nutrition Examination Survey, 1999 to 2004. J Am Coll Surg. 2008 Dec;207(6):928-34.

4. Sullivan PW, Ghushchyan VH, Ben-Joseph R. The impact of obesity on diabetes, hyperlipidemia and hypertension in the United States. Qual Life Res. 2008 Oct;17(8):1063-71.

5. Ackroyd R, Mouiel J, Chevallier JM, Daoud F. Cost-effectiveness and budget impact of obesity surgery in patients with type-2 diabetes in three European countries. Obes Surg. 2006 Nov;16(11):1488-503.

6. Franz MJ, VanWormer JJ, Crain AL, Boucher JL, Histon T, Caplan W, et al. Weight-loss outcomes: a systematic review and meta-analysis of weight-loss clinical trials with a minimum 1-year follow-up. J Am Diet Assoc. 2007 Oct;107(10):1755-67.

7. Gloy VL, Briel M, Bhatt DL, Kashyap SR, Schauer PR, Mingrone G, et al. Bariatric surgery versus non-surgical treatment for obesity: a systematic review and meta-analysis of randomised controlled trials. BMJ. 2013 Oct 22;347:f5934.

8. Buchwald, H. The evolution of metabolic/bariatric surgery. Obes Surg. 2014 Aug;24(8):1126-35.

9. Sjöström L, Peltonen M, Jacobson P, Ahlin S, Andersson-Assarsson J, Anveden $\AA$, et al. Association of bariatric surgery with long-term remission of type 2 diabetes and with microvascular and macrovascular complications. JAMA. 2014 Jun 11;311(22):2297-304.

10. Melissas J. IFSO guidelines for safety, quality, and excellence in bariatric surgery. Obes Surg. 2008 May;18(5):497-500.

11. Anděl J. Fundamentals of mathematical statistics. Prague: Matfyzpress; 2005. (In Czech.)

12. Czech Diabetes Society. Recommended process of care for type 2 diabetes mellitus. [Internet]. Prague: ČLS J.E.Purkyně; 2012 [cited 2015 Jun 20]. Available from: http://www.diab.cz/dokumenty/dm2_12.pdf. (In Czech.)

13. Buchwald H, Avidor Y, Braunwald E, Jensen MD, Pories W, Fahrbach K, et al. Bariatric surgery: a systematic review and meta-analysis. JAMA. 2004 Oct 13;292(14):1724-37.

14. Peterli R, Steinert RE, Woelnerhanssen B, Peters T, Christoffel-Courtin C, Gass M, et al. Metabolic and hormonal changes after laparoscopic Rouxen-Y gastric bypass and sleeve gastrectomy: a randomized, prospective trial. Obes Surg. 2012 May;22(5):740-8.

15. Vanguri P, Brengman M, Oiticica C, Wickham EP 3rd, Bean MK, Lanning DA. Laparoscopic gastric plication in the morbidly obese adolescent patient. Semin Pediatr Surg. 2014 Feb;23(1):24-30.

16. Bradnova O, Kyrou I, Hainer V, Vcelak J, Halkova T, Sramkova P, et al. Laparoscopic greater curvature plication in morbidly obese women with type 2 diabetes: effects on glucose homeostasis, postprandial triglyceridemia and selected gut hormones. Obes Surg. 2014 May;24(5):718-26.
17. de Aquino LA, Pereira SE, de Souza Silva J, Sobrinho CJ, Ramalho A Bariatric surgery: impact on body composition after Roux-en-Y gastric bypass. Obes Surg. 2012 Feb;22(2):195-200.

18. Shah N, Greenberg JA, Leverson G, Statz AK, Jolles SA, Funk LM. Weight loss after bariatric surgery: a propensity score analysis. J Surg Res. 2016 May 15;202(2):449-54.

19. Bužga M, Marešová $P$, Seidlerová A, Zonča P, Holéczy P, Kuča K. The influence of methods of bariatric surgery for treatment of type 2 diabetes mellitus. Ther Clin Risk Manag. 2016 Apr 15;12:599-605.

20. Zhang F, Strain GW, Lei W, Dakin GF, Gagner M, Pomp A. Changes in lipid profiles in morbidly obese patients after laparoscopic sleeve gastrectomy (LSG). Obes Surg. 2011 Mar;21(3):305-9.

21. Vidal J, Ibarzabal A, Romero F, Delgado S, Momblán D, Flores L, et al Type 2 diabetes mellitus and the metabolic syndrome following sleeve gastrectomy in severely obese subjects. Obes Surg. 2008 Sep;18(9):107782.

22. Abbatini F, Rizzello M, Casella G, Alessandri G, Capoccia D, Leonetti F, et al. Long term effects of laparoscopic sleeve gastrectomy, gastric bypass, and adjustable gastric banding on Type 2 diabetes. Surg Endosc. 2010 May;24(5):1005-10.

23. Lee WJ, Chong K, Ser KH, Lee YC, Chen SC, Chen JC, et al. Gastric bypass vs sleeve gastrectomy for type 2 diabetes mellitus: a randomized controlled trial. Arch Surg. 2011 Feb;146(2):143-8.

24. Bužga M, Švagera Z, Tomášková H, Hauptman K, Holéczy P. Metabolic effects of sleeve gastrectomy and laparoscopic greater curvature plication: an 18-month prospective, observational, open-label study. Obes Surg. 2017 Dec;27(12):3258-66.

25. Gaur A, Naidu CS, Rao PP, Sharma S, Singh AK, Trehan V, et al. The effect of laparoscopic sleeve gastrectomy (LSG) on glycemic control in morbidly obese patients. Int J Surg. 2016 Apr;28:131-5.

26. Slater BJ, Bellatorre N, Eisenberg D. Early postoperative outcomes and medication cost savings after laparoscopic sleeve gastrectomy in morbidly obese patients with type 2 diabetes. J Obes. 2011;2011:350523.

27. Fried M, Dolezalova K, Buchwald JN, McGlennon TW, Sramkova P, Ribaric G. Laparoscopic greater curvature plication (LGCP) for treatment of morbid obesity in a series of 244 patients. Obes Surg. 2012 Aug;22(8):1298-307.

28. Bužga M, Holéczy P, Švagera Z, Zonča P. Laparoscopic gastric plication and its effect on saccharide and lipid metabolism: a 12-month prospective study. Wideochir Inne Tech Maloinwazyjne. 2015 Sep;10(3):398-405.

Received November 22, 2015 Accepted in revised form February 7, 2018 